Research Article

\title{
Levetiracetam: an open label study on safety and efficacy in newly diagnosed partial onset seizures as monotherapy
}

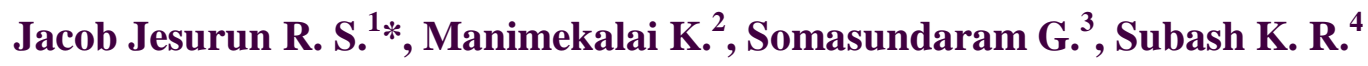

\begin{abstract}
${ }^{1}$ Department of Pharmacology, Shri Sathya Sai Medical College and Research Institute, Tamil Nadu, India

${ }^{2}$ Department of Pharmacology, Mahatma Gandhi Medical College and Research Institute, Puducherry, India

${ }^{3}$ Department of Pharmacology, Sri Lakshmi Narayana Institute of Medical Sciences,

Puducherry, India

${ }^{4}$ Department of Pharmacology, SVIMS-Sri Padmavathi Medical College and Hospital for Women, Tirupati, India
\end{abstract}

Received: 24 May 2016 Accepted: 17 June 2016

*Correspondence to: Dr. Jacob Jesurun R. S., Email: drrsjj@gmail.com

Copyright: (C) the author(s), publisher and licensee Medip Academy. This is an openaccess article distributed under the terms of the Creative Commons Attribution NonCommercial License, which permits unrestricted noncommercial use, distribution, and reproduction in any medium, provided the original work is properly cited.

\begin{abstract}
Background: The Common neurological disorder in pediatric population is epilepsy. Despite having many medications and with recent approval of levetiracetam (LEV) as an adjunctive treatment in children, there is a need to evaluate safety and efficacy of this drug in Indian population. The aim was to study the efficacy and tolerability of levetiracetam as monotherapy, in newly diagnosed partial onset seizures.
\end{abstract}

Methods: Newly diagnosed partial seizure patients attending the neurology outpatient department were considered for the study based on the inclusion criteria. After the patients were started on the minimal therapeutic dose of the allocated drug LEV $500 \mathrm{mg}$ twice daily over a period of 2 weeks, if there is no adequate seizure control, the dose of medication was further stepped up. Dose level 2 was taken as $1000 \mathrm{mg}$ twice daily for levetiracetam over next 2 weeks. Dose level 3, $1500 \mathrm{mg}$ twice daily for levetiracetam for the final 2 weeks (Maximum dose tried). After 6 weeks of dose stabilization, all patients had a final evaluation at the end of 6 months to assess for 6 month seizure free period. Results: Out of 37 subjects who had first visit eligibility on screening 5 did not give consent 2 were in exclusion criteria with 30 involved in study three were lost in follow up. Among 28 children in levetiracetam group $17(62.96 \%)$ had seizure control at 6 months with dose level $1(20 \mathrm{mg} / \mathrm{kg} /$ day $)$ itself. 8 patients (25.92\%) had control on dose level $2(30 \mathrm{mg} / \mathrm{kg} /$ day). 2 patients $(7.40 \%)$ had seizure control at maximum dose level 3 (40 mg/kg/day). In 1 patient, seizures were not controlled in spite of maximum dose. This patient was started on alternative drugs. The commonest discomfort faced by the subjects include nausea $14(51.85 \%)$, drowsiness $11(40.74 \%)$, unsteadiness $6(27 \%)$, diplopia 6 $(20 \%)$ and headache $6(20 \%)$.

Conclusions: Though the present study is an analysis of small population and open labeled, the results are clear levetiracetam as monotherapy is effective in majority of study population at a dose of 20 to $40 \mathrm{mg} / \mathrm{kg} / \mathrm{day}$. The cost effectiveness and safety of the drug has also given promising results for its usage among pediatric age group. A study on large group with comparison to existing gold standard drugs with proven efficacy in children like gabapentin, topiramate, oxcarbazepine and lamotrigine can give more information as monotherapy and its use as adjunctive drug.

Keywords: Levetiracetam (LEV), Children's, Epilepsy, Partial seizure

\section{INTRODUCTION}

Among various neurological disorders observed in paediatric population, epilepsy is the common problem encountered. ${ }^{1,2}$ Though the availability of new antiepileptic drugs from past decades has proven efficacious as an adjuvant along with mainstay drugs. ${ }^{3}$ The studies of newer antiepileptic drugs as monotherapy established few effective among adult population. ${ }^{4,5}$ For children very few drugs are available as monotherapy among which the newer addition of levetiracetam has gained more popularity among paediatricians. ${ }^{6,7}$ And even though we have gained enough trust on levetiracetam from the observations of adult population, application of the same in paediatric population will differ with age, etiology and co morbid conditions. ${ }^{8}$ 
Hence the aim of the study was to evaluate the safety and efficacy of the newer drug levetiracetam as monotherapy in south Indian paediatric population.

\section{METHODS}

Newly diagnosed partial seizure patients attending the neurology outpatient department were considered for the study based on the inclusion criteria.

\section{Inclusion criteria}

- Newly diagnosed patients of both gender with partial seizures with or without secondary generalisation

- $\quad<16$ years of age.

\section{Exclusion criteria}

- Patients with co-morbid conditions.

- Patients with other type of seizures.

A Sample size of 37 patients in the levetiracetam group was observed for safety and efficacy following a detailed history taken from the patients and relatives or witnesses regarding onset, duration, frequency, last seizure and other related co morbid conditions and relevant past and family history.

All the patients underwent general and neurological examination, hematological (complete blood count) and biochemical analysis (serum electrolytes, blood urea, serum creatinine, random blood glucose). Imaging of the brain, CT head was done in all patients and MRI was done when indicated.

The patients were provided with complete information regarding the cost of the drugs and regarding the period for which they may have to take the drugs even after the completion of the study. Complete transparency regarding the cost and effects of the drugs used in the study were maintained between the investigator and the patient.

Purpose of the study and the cost involved was clearly explained to each participant in their regional language and assured that information collected from them will be kept confidential. Ethical committee approved consent form in the regional language was obtained from each participant and then information was collected. After this, the patients willing to afford the drug and participate in the study were selected.

The patients were started on the minimal therapeutic dose of levetiracetam $20 \mathrm{mg} / \mathrm{kg} /$ day over a period of 2 weeks. They were asked to follow up 2 weekly till six weeks. In each visit during stabilization period, if there is no adequate seizure control, the dose of medication was further stepped up. Dose level 2, was taken as $30 \mathrm{mg} / \mathrm{kg} /$ day for levetiracetam over next 2 weeks. Dose level $3,40 \mathrm{mg} / \mathrm{kg} /$ day for levetiracetam for the final 2 weeks (maximum dose tried).

Henceforth monthly visits were done for ensuring compliance, evaluation for recurrence of seizures and for incidence of side effects. The compliance was monitored strictly by directing the patient/caretaker to maintain a log book for consumption of the drugs and was also instructed to bring the empty foils during the successive visits. In case of recurrence of seizures after achievement of maximum dose, patient was started on another antiepileptic drug according to standard guidelines. These patients were considered to have drug failure with monotherapy. After 6 weeks of dose stabilization, all patients had a final evaluation at the end of 6 months to assess for 6 month seizure free period.

All patients recorded number and type of any seizures and adverse events (AEs) using daily record cards. Adverse effects were also assessed at each visit using a non-structured interview. During every visit, the patients were thoroughly examined and any necessary investigations required were done promptly. The investigator's phone number was given to all the patients and he was available for assistance round the clock.

If the seizures still persisted, the patient was considered to have failed on monotherapy and the second drug was added along with the first drug and its dosage was gradually increased up to its maximum therapeutic dosage/maximum tolerable dosage depending on the clinical response of the patient. Now the initial drug was gradually down titrated and finally stopped over a period of time or was continued along with the second drug depending on the clinical response and tolerability of the individual patient. If at any point of time during followup, an unexpected side effect like an idiosyncratic, hypersensitivity or dose related reaction occurred, the drug was withdrawn and a second drug was started.

The primary outcome measures of time to achieve a 6 months remission of seizures and the secondary outcome measures of incidence of clinically important adverse events date were systematically analyzed. The study was conducted at Mahatma Gandhi Medical College and Research Institute, Puducherry, India.

Patient recruitment was started on March 2010 after duly obtaining approval from institutional ethics committee. The last patients follow up ended on July 2011. Patients were chosen according to the study protocol considering the inclusion and exclusion criteria mentioned in the methods of study. Data was collected meticulously and statistically analyzed for percentage of subjects who had seizure control and those dose levels, including safety assessment evaluation of adverse events and their severity by investigator during each visit. 


\section{RESULTS}

A total of 37 subjects were considered for the study out of which five subjects were not willing for enrolment in the study and 2 were in exclusion criteria. Hence with study subject strength of 30, the demographic and baseline characteristics of clinical features were recorded as shown in Table 1.

A total of 2 subjects were lost in follow up at $2^{\text {nd }}$ week. Among the total 28 subjects who completed regular follow up 17 subjects responded to LEV dose level I without seizure, 8 subjects responded to LEV dose level II without seizures, 2 subjects responded to LEV dose level III without seizure and 1 subject continued to have episodes of seizure even at dose level III as shown in Table 2.
Table 1: Demographic and baseline clinical characteristics.

\begin{tabular}{|c|c|}
\hline Characteristics & LEV N= 30 \\
\hline \multicolumn{2}{|l|}{ Seizure type } \\
\hline Simple partial & $8(26.66 \%)$ \\
\hline Complex partial & $23(76.66 \%)$ \\
\hline $\begin{array}{l}\text { Partial secondarily } \\
\text { generalized }\end{array}$ & $6(20 \%)$ \\
\hline $\begin{array}{l}\text { Age range at study entry } \\
\text { (years) }\end{array}$ & $\begin{array}{l}4.5 \text { to } 12.8 \text { years. } \\
\text { Mean } 10.0 \pm 3.2\end{array}$ \\
\hline $\begin{array}{l}\text { Age range at onset of } \\
\text { epilepsy }\end{array}$ & $\begin{array}{l}0 \text { to } 12 \text { years. } \\
\text { Mean } 5.0 \pm 2.6\end{array}$ \\
\hline $\begin{array}{l}\text { Age range for duration of } \\
\text { epilepsy }\end{array}$ & $\begin{array}{l}0 \text { to } 12 \text { years } \\
\text { Mean } 6.0 \pm 2.3\end{array}$ \\
\hline $\begin{array}{l}\text { Age range of partial } \\
\text { seizures per week }\end{array}$ & $\begin{array}{l}1.5 \text { to } 147 \\
\text { Mean } 8.6 \pm 32\end{array}$ \\
\hline
\end{tabular}

LEV-levetiracetam

Table 2: Levetiracetam dose and seizure frequency.

\begin{tabular}{|c|c|c|c|c|c|c|c|c|c|c|}
\hline \multirow{3}{*}{$\begin{array}{l}\text { Patient } \\
\text { No. } \\
(\mathrm{N}=30)\end{array}$} & \multicolumn{9}{|c|}{ Seizure frequency/week } & \multirow{3}{*}{$\begin{array}{l}\text { Final } \\
\text { LEV } \\
\text { dose } \\
\text { mg/kg/day }\end{array}$} \\
\hline & \multirow[b]{2}{*}{ Baseline } & \multicolumn{2}{|l|}{$2^{\text {nd }}$ week } & \multicolumn{2}{|c|}{$4^{\text {th }}$ week } & \multicolumn{2}{|l|}{$6^{\text {th }}$ week } & \multicolumn{2}{|l|}{$26^{\text {th }}$ week } & \\
\hline & & Evaluation & $\begin{array}{l}\% \\
\text { change }\end{array}$ & Evaluation & $\begin{array}{l}\% \\
\text { change }\end{array}$ & Evaluation & $\begin{array}{l}\% \\
\text { change }\end{array}$ & Evaluation & $\begin{array}{l}\% \\
\text { change }\end{array}$ & \\
\hline 1 & 56.8 & 31.0 & 45 & 0 & 0 & 0 & 0 & 0 & 0 & 30 \\
\hline 2 & 24.5 & 0 & 0 & 0 & 0 & 0 & 0 & 0 & 0 & 20 \\
\hline 3 & 66.5 & 0 & 0 & 0 & 0 & 0 & 0 & 0 & 0 & 20 \\
\hline 4 & 10 & 8 & 20 & 10 & $25 \uparrow$ & 7.5 & 34 & 8 & $6.66 \uparrow$ & $\begin{array}{l}\text { Drug } \\
\text { change }\end{array}$ \\
\hline 5 & 34.5 & 0 & 0 & 0 & 0 & 0 & 0 & 0 & 0 & 20 \\
\hline 6 & 94 & 0 & 0 & 0 & 0 & 0 & 0 & 0 & 0 & 20 \\
\hline 7 & 56 & 0 & 0 & 0 & 0 & 0 & 0 & 0 & 0 & 20 \\
\hline 8 & 42 & 25 & 40.47 & 0 & 0 & 0 & 0 & 0 & 0 & $30 *$ \\
\hline 9 & 30.20 & 22.5 & 25.49 & 0 & 0 & 0 & 0 & 0 & 0 & $30 *$ \\
\hline 10 & 63.3 & 0 & 0 & 0 & 0 & 0 & 0 & 0 & 0 & 20 \\
\hline 11 & 8.2 & 0 & 0 & 0 & 0 & 0 & 0 & 0 & 0 & 20 \\
\hline 12 & 3.4 & 0 & 0 & 0 & 0 & 0 & 0 & 0 & 0 & 20 \\
\hline 13 & 8.6 & 0 & 0 & 0 & 0 & 0 & 0 & 0 & 0 & 20 \\
\hline 14 & 65 & 27.5 & 57.69 & 0 & 0 & 0 & 0 & 0 & 0 & $30 *$ \\
\hline 15 & 15 & 9.5 & 36.66 & 0 & 0 & 0 & 0 & 0 & 0 & $30 *$ \\
\hline 16 & 34 & 0 & 0 & 0 & 0 & 0 & 0 & 0 & 0 & 20 \\
\hline 17 & 45 & 0 & 0 & 0 & 0 & 0 & 0 & 0 & 0 & 20 \\
\hline 18 & 27 & 12.6 & 53.33 & 0 & 0 & 0 & 0 & 0 & 0 & $30 *$ \\
\hline 19 & 44 & 0 & 0 & 0 & 0 & 0 & 0 & 0 & 0 & 20 \\
\hline 20 & 9.5 & 0 & 0 & 0 & 0 & 0 & 0 & 0 & 0 & 20 \\
\hline 21 & 23 & 0 & 0 & 0 & 0 & 0 & 0 & 0 & 0 & 20 \\
\hline 22 & 6.6 & 3.5 & 46.96 & 0 & 0 & 0 & 0 & 0 & 0 & $30 *$ \\
\hline 23 & 64 & 0 & 0 & 0 & 0 & 0 & 0 & 0 & 0 & 20 \\
\hline 24 & 12.2 & 0 & 0 & 0 & 0 & 0 & 0 & 0 & 0 & 20 \\
\hline 25 & 8 & 6.2 & 22.50 & 3.0 & 51.61 & 0 & 0 & 0 & 0 & $40 * *$ \\
\hline 26 & 10 & 8.5 & 15.00 & 8 & 5.88 & 0 & 0 & 0 & 0 & $40 * *$ \\
\hline 27 & 16.5 & 0 & 0 & 0 & 0 & 0 & 0 & 0 & 0 & 20 \\
\hline 28 & 50.50 & 32.60 & 35.44 & 0 & 0 & 0 & 0 & 0 & 0 & $30 *$ \\
\hline 29 & 22 & NA & NA & NA & NA & NA & NA & NA & NA & 20 \\
\hline 30 & 14 & NA & NA & NA & NA & NA & NA & NA & NA & 20 \\
\hline
\end{tabular}

LEV- Levetiracetam. *Dose level I, **Dose Level II, ***Dose Level III, NA-Not Available lost follow up 
Table 3: Recorded adverse event.

\begin{tabular}{|ll|}
\hline Adverse events & Incidence no (\%) \\
\hline Nausea & $14(51.85)$ \\
\hline Drowsiness & $11(40.74)$ \\
\hline Unsteadiness & $06(20.00)$ \\
\hline Diplopia & $06(20.00)$ \\
\hline Headache & $06(20.00)$ \\
\hline Infection & $08(26.66)$ \\
\hline Skin rashes & $02(06.66)$ \\
\hline
\end{tabular}

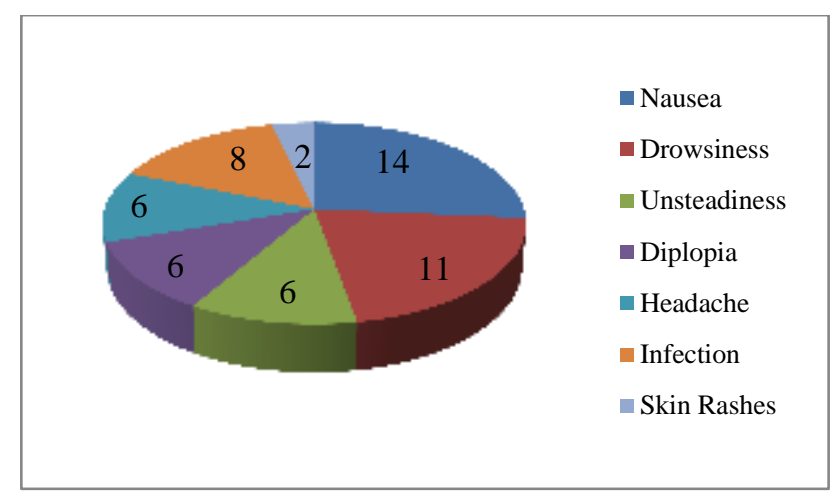

Figure 1: LEV: adverse events.

The recorded adverse event on the 30 study subjects revealed during follow-ups, physical, neurological and laboratory values revealed stable ECG values (Table 3). In one patient seizure was not controlled at high dose LEV $40 \mathrm{mg} / \mathrm{kg} / \mathrm{day}$. The recorded and reported adverse events were nausea $51.85 \%$, drowsiness $40.74 \%$, unsteadiness, diplopia, headache in $20 \%$ and infection in $26.66 \%$ of subjects.

\section{DISCUSSION}

A pilot cost effective analysis was conducted with the inputs from the consultant neurologist, Dr. Murugesan (Co-Investigator). The results were expressed as cost/ outcome or units of effectiveness revealed following results: for treatment levetiracetam: Rs. 595/9=66. Where numerator depicts the cost per month of the drug and the denominator depicts the no. of seizure free patients at the end of one month of treatment. Lower the units better the cost effective outcome (66). ${ }^{9}$ This has been applied to the better treatment profile with respect to sodium valproate and phenytoin where sodium valproate is preferred in spite of its higher cost than phenytoin because of its better adverse effect profile. Similar concept can be extrapolated to the present study. Hence levetiracetam proves to be more cost effective.

The primary reason is withdrawal from study of the drug for reasons of unacceptable adverse events or inadequate seizure control or a combination of the two and on these criteria. Where in the current study 2 patients discontinued due to drug induced skin rashes at $2^{\text {nd }}$ week visit. 1 patient lost to follow up for reasons unknown.
1 patient continued to develop seizures, in spite of highest possible dose increment and good compliance. The patient was switched over to other appropriate antiepileptic drugs. The primary outcome is $10 \%(3 / 30)$ and at the end of $27^{\text {th }}$ week 27 patients $(86.66 \%)$ were seizure free at the final evaluation. 2 patients had discontinued treatment while 1 patient had seizure episode even in the maximum dose hence switched over another drug, due to lack of efficacy. The seizure freedom when analyzed by dose level in levetiracetam most of the patients $17(56.66 \%)$ had seizure control at 6 months with dose level 1 (20 $\mathrm{mg} / \mathrm{kg} /$ day $)$ itself. 8 patients (23.33\%) had control on dose level 2 (30 mg/kg/day). 2 patients $(6.67 \%)$ had seizure control at maximum dose level 3 (40 mg/kg/day). In 1 patient, seizures were not controlled in spite of maximum dose. This patient was started on alternative drugs. The drug levetiracetam as monotherapy was promisingly effective and our findings are similar to other studies of older population. ${ }^{10}$ Many controlled clinical trials with levetiracetam as an add on drug to the treatment regimen has proved its efficacy in controlled clinical trials among adult population. ${ }^{11,12}$ Coming on to the safety part the adverse effects profile was meticulously followed up during each visit Unsteadiness is higher in levetiracetam, psychiatric symptoms found were sleeplessness, aggressiveness, depression was found in 5 patients in levetiracetam, psychotic symptoms like mania, anxiety described in other studies were not found in this study. Skin rashes were found in 2 patients who had to discontinue treatment. The commonest adverse events recorded are nausea $51.85 \%$ followed by drowsiness $40.74 \%$, unsteadiness, diplopia, in $20 \%$ and infection in $26.66 \%$ of subjects. The infection that is observed among study subjects are common cold with mild upper respiratory tract infection and this information is based on 26 week observation. Such an incidence among children population may not have any association with the study drug and such incidence were also observed among children's who are on other antiepileptic drugs. ${ }^{13}$

Though the present study is an analysis of small population and open labelled, the results are clear that levetiracetam as monotherapy is effective in majority of study population at a dose of 20 to $40 \mathrm{mg} / \mathrm{kg} / \mathrm{day}$. The cost effectiveness and safety of the drug has also given promising results for its usage among pediatric age group. A study on large group with comparison to existing gold standard drugs with proven efficacy in children like gabapentin, topiramate, oxcarbazepine and lamotrigine can give more information as monotherapy and its use as adjunctive drug. ${ }^{14}$

\section{Funding: No funding sources Conflict of interest: None declared \\ Ethical approval: The study was approved by the Institutional Ethics Committee}




\section{REFERENCES}

1. Shinnar S, Pellock JM. Update on the epidemiology and prognosis of pediatric epilepsy. J Child Neurol. 2002;17(1):4-17.

2. CDC. targeting epilepsy: improving the lives of people with one of the nation's most common neurological conditions. 2011. Available from: http://www.cdc.gov/chronicdisease/resources/public ations/AAG/epilepsy.htm. Accessed on 23 January 2013.

3. French JA, Kanner AM, Bautista J. Efficacy and tolerability of the new antiepileptic drugs II: treatment of refractory epilepsy: report of the therapeutics and technology assessment subcommittee and quality standards subcommittee of the American academy of neurology and the American epilepsy society. Neurology. 2004;62(8):1261-73.

4. Beydoun A. Monotherapy trials of new antiepileptic drugs. Epilepsia. 1997;38(9):21-31.

5. Chadwick DW. Monotherapy clinical trials of new antiepileptic drugs: design, indication and controversies. Epilepsia. 1997;38(9):16-20.

6. Garza JE, Nordli DR, Rating D. Adjunctive levetiracetam in infants and young children with refractory partial-onset seizures. Epilepsia. 2009;50(5):1141-9.

7. Perry MS, Benatar M. Efficacy and tolerability of levetiracetam in children younger than 4 years: a retrospective review. Epilepsia. 2007;48(6):1123-7.
8. Pellock JM. Drug treatment in children. In: Engel J, Pedley TA eds. Epilepsy: a comprehensive textbook. Philadelphia:Lippincott-Raven;1997:1205-10.

9. Berger MI. Economic analysis of health care technology; A report on principles. Ann Intern Med. 1995;122;61-70.

10. Cereghino JJ, Biton V, Abou-khalil B. Levetiracetam for partial seizures: results of a double blind, randomized clinical trial. Neurology. 2000;55:236-42.

11. Shorvon SD, Janz D, Lowenthal A. Multicenter double blind randomized, placebo-controlled trial of levetiracetam as add-on therapy in patient with refractory partial seizures. Epilepsy. 2000;41:117986.

12. Ben ME, Falter U. Efficacy and tolerability of Levetiracetam $3000 \mathrm{mg} /$ day in patient with refractory partial onset seizures: a multicenter, double blind, responder-selected study evaluating monotherapy. Epilepsia. 2000;41:1276-83.

13. Donaldson JA, Glauser TA, Olberding LS. Lamotrigine adjunctive therapy in childhood epileptic encephalopathy (the lennox-gastaut syndrome). Epilepsia. 1997;38:68-73.

14. Elterman RD, Glauser TA, Wylie E. A double blind, randomized trial of topiramate as adjunctive therapy for partial-onset seizures in children. Neurology. 1999;52:13338-44.

Cite this article as: Jesurun JRS, Manimekalai K, Somasundaram G, Subash KR. Levetiracetam: an open label study on safety and efficacy in newly diagnosed partial onset seizures as monotherapy. Int J Basic Clin Pharmacol 2016;5:1249-53. 